\title{
ALCANCES DE LA ACCIÓN PSICOSOCIAL EN EL TRABAJO
}

Liz Giomaira Montenegro Losada Directora Nacional curso Acción Psicosocial y Trabajo Correo electrónico: liz.montenegro@unad.edu.co ORCID ID: 0000-0002-6393-1860

Julio de 2018

La acción psicosocial en el contexto del trabajo, desde la perspectiva del programa de Psicología de la UNAD, es comprendida como el conjunto de prácticas o estrategias psicológicas que buscan incidir en las condiciones y dinámicas de interacción de los individuos dentro de los contextos de trabajo, con la finalidad de transformar, mejorar y/o aportar a cambiar esta realidad en caso de ser necesario, fundamentados en un proceso crítico derivado de un diagnóstico contextual.

Así, la acción en este contexto se refiere al conjunto de prácticas o estrategias psicológicas que un psicólogo Unadista puede proponer desde la disciplina y que incluye la atención y el acompañamiento a las problemáticas psicosociales que surgen en los espacios laborales y que buscan incidir sobre las condiciones y dinámicas de interacción, de los individuos dentro de los contextos de trabajo. Para esto, se deben revisar los procesos y las situaciones derivadas de las inter-relaciones individuo-organización e individuo-individuo bajo la concepción del paradigma sistémico de Bertalanffy, con la finalidad de transformar, mejorar y/o aportar a cambiar esta realidad en caso de ser necesario, fomentando toda acción para contribuir a mejorar el contexto actual que se estudia partiendo del diagnóstico contextual.

Por lo anterior, el psicólogo que adelanta acciones psicosociales en el trabajo busca comprender, explicar y evaluar las condiciones que inciden en el bienestar y en los fenómenos subyacentes a la vida en el trabajo de los individuos para contribuir con la formulación y puesta en marcha de acciones que dinamicen las situaciones encontradas, favoreciendo la autogestión y la sana convivencia en este contexto. 
Para lograr esto, es pertinente considerar una metodológica que facilite la comprensión de la realidad contextual del trabajador en su ámbito laboral y la posterior puesta en marcha de acciones que conlleven al fomento de la vida laboral activa, participativa, sana y orientada a los logros organizacionales en donde se privilegie el bienestar del trabajador. Para esto, se describen a continuación las fases que pueden seguirse en una acción psicosocial en el contexto del trabajo:

1. Diagnóstico contextual: que integre los siguientes tópicos: Intrapersonal (rasgos de personalidad, intereses y necesidades personales, anhelos, sentimientos, emociones, proyecciones, aspiraciones, expectativas, cogniciones, aptitudes, competencias, aprendizajes, rendimiento, satisfacción y bienestar). Interpersonal (relaciones interpersonales, comunicación, sentido de cooperación y competitividad, persecución, acoso laboral). Grupal (equipos de trabajo, liderazgo). Organizacional (cultura y ambiente laboral, desarrollo organizacional, factores ergonómicos, tecnología, orientación al cambio, gestión del talento humano, relaciones laborales, resolución de conflictos, negociación, etc). Macro-social (mercado de trabajo, ideologías y políticas socio-laborales, coyuntura del empleo).

2. Caracterización de la población: Teniendo en cuenta lo hallado en el diagnóstico contextual conviene describir los aspectos relevantes de los actores o beneficiarios del acompañamiento.

3. Establecer el propósito de la acción psicosocial: Lo cual significa presentar claramente qué es lo que se desea alcanzar. Ello marcará el horizonte de lo que se realizará.

4. Definición de la propuesta a trabajar desde la acción psicosocial (Modelos de intervención): Diseño del plan de acción en coherencia con las necesidades encontradas fundamentado desde la disciplina y teniendo en cuenta las competencias del estudiante en formación. 
5. Referentes contextuales y teóricos que permitirán dar sustento a la misma: Se debe plantear cuál es el soporte teórico que da sentido a las acciones propuestas y de qué manera se articulan con lo que se realizará.

6. Seguimiento y evaluación: Fase en la que se revisa y analiza el logro del propósito, además se puntualiza en los aspectos a mejorar de lo planteado en la propuesta y se establece el impacto alcanzado con las acciones implementadas. Esto se debe hacer en dos vías, desde la posición del psicólogo y desde la experiencia de la organización o el grupo social.

La metodología utilizada para hacer acción psicosocial en el contexto de trabajo, suele ser de preferencia cualitativa, toda vez que permite la descripción de las realidades de tal manera que sea posible lograr una aproximación “...a esa realidad compleja, sin que se aspire a una verdad como adecuación, ni a la construcción de leyes y teorías universales explicativas de los fenómenos, sino a interpretaciones densas de los mismos" (Geertz, 1989, citado por Villa, 2012). Entendiendo que la interpretación densa “... permite presentar el fenómeno en toda la riqueza de sus detalles e implicaciones, abarcando sus relaciones contextuales y sus diferentes niveles de significado" (Gibaja, 2005, p. 21. Citado por Villegas y González, 2011);

De esta manera, se articulan técnicas que facilitan el reconocimiento y la actuación en la situación encontrada:

La entrevista psicológica: permite conocer la situación o realidad desde la mirada de los actores mediante la evaluación de aspectos relevantes que faciliten la contextualización requerida. La entrevista puede ser semi-estructurada, lo que facilita al entrevistador formular preguntas nuevas o complementarias en caso de ser necesario para profundizar en el contenido del discurso, por su lado la entrevista estructurada se ciñe a un formato previamente establecido del cual no se debe salir.

La observación: se concibe como una técnica exploratoria, que posibilita recoger información de la cotidianidad de los individuos y contribuye a comprender el contexto con sus diferentes dinámicas de interacción. Se deben tener las unidades de conducta y/o interacción que se observan. 
La cartografía Social: es una técnica dialógica, participativa y colaborativa que conduce “....a la reflexión, organización y acción alrededor de un espacio físico y social específico" " . permite proponer, desde una perspectiva transdisciplinaria, preguntas y perspectivas críticas para abordar los conflictos..." (Vélez \& otros, 2012).

El árbol de problemas: es una estrategia que facilita la participación de todos los involucrados en la identificación de los problemas o necesidades más relevantes con sus correspondientes causas y consecuencias, ello facilita la implementación de acciones efectivas para intervenirlas.

Juego de roles: es la representación y puesta en escena de situaciones de la cotidianidad de los individuos y que ameritan ser analizadas por su relevancia e impacto.

El taller: herramienta que busca aprender a aprender, es el escenario que propicia la reflexión-acción para revisar situaciones y estudiar posibles opciones de mejora, involucrando a los actores involucrados.

Sociodrama: hace referencia a una representación o simulación de algún hecho real para "...hacerle un profundo análisis. Implica el manejo del espacio íntimo, en tanto exige una ubicación espacial que permita una visión cercana entre los participantes, generándose formas de interacción y de intercambio que inciden en los resultados esperados" (García De Vicente, et at.,1998, p. 170)

Lo anterior, ilustra algunas de las técnicas que se pueden utilizar para elaborar el diagnóstico contextual pero también para realizar la acción psicosocial. Ello exige que el encargado de esta labor en un contexto específico, en este caso el psicólogo, sea “...mediador-facilitador y canalizador-orientador de los fenómenos que se dan en el mismo; así, el grupo se convierte en sujeto activo de su aprendizaje, de una forma recíproca y cíclica con una comunicación bidireccional que facilita el intercambio de información y el crecimiento individual y/o grupal." (García De Vicente, et at.,1998) 
Ante lo descrito, se espera lograr a través de la acción psicosocial en el trabajo que, en primer lugar, el estudiante identifique los procesos y las responsabilidades propias del Psicólogo en dicho campo de actuación y que además sepa cómo describir, comprender y transformar las dinámicas laborales a partir de lo encontrado en el diagnóstico contextual. Así mismo, se busca que plantee acciones para brindar acompañamiento psicosocial, en el ámbito del trabajo, debidamente sustentadas desde la disciplina.

Finalmente, "siguiendo el principio de incertidumbre de Heisenberg cualquier intervención que se realice sobre un grupo modificará su dinámica en alguno de los elementos principales de éstos, como son: los miembros, subgrupos, canales de comunicación, tareas a realizar y barreras (Lewin, 1952. Citado en García, L. \& otros (1998)).

\section{CIBERGRAFIA}

García, L. \& otros. (1998) El sociodrama como técnica de intervención socloeducativa. Cuadernos de trabajo Social, recuperado de http://revistas.ucm.es/index.php/CUTS/article/viewFile/CUTS9898110165A/8240

Vélez, I. \& otros (2012) Cartografía social como metodología participativa y colaborativa de investigación en el territorio afrodescendiente de la cuenca alta del río Cauca. Cuadernos de Geografía- Revista Colombiana de Geografía Recuperado de http://www.scielo.org.co/pdf/rcdg/v21n2/v21n2a05.pdf

Villa, J. (2012). La acción y el enfoque psicosocial de la Intervención en contextos sociales: ¿podemos pasar de la moda a la precisión teórica, Epistemológica y metodológica? El Ágora USB. Recuperado de https://dialnet.unirioja.es/servlet/articulo?codigo=4550239

Villegas, M. y González, J. (2011). La investigación cualitativa de la vida cotidiana, medio para la construcción del conocimiento sobre lo social a partir de lo individual. Psicoperspectivas, Individuo y Sociedad. Recuperado de http://www.psicoperspectivas.cl/index.php/psicoperspectivas/article/view/147/175 


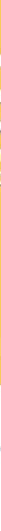

